http://jmscr.igmpublication.org/home/ ISSN (e)-2347-176x ISSN (p) 2455-0450 crossref DOI: https://dx.doi.org/10.18535/jmscr/v9i5.04

\title{
A Study on Austin Moore's Prosthesis: Pros and Cons
}

\section{Authors \\ Dr Rahmat Ali (Ms (Ortho), MCh (Ortho)) Fellowship Spine ${ }^{1}$ Dr Abhishek Kumar Barnwal (MD (Anaesthesiology)) ${ }^{\text {* }}$}

${ }^{1}$ Professor and H.O.D (Ortho department), MaharishiVashishtha Autonomous State Medical College, Basti, UP

\author{
${ }^{2}$ Assistant Professor, Maharishi Vashishtha Autonomous State Medical College, Basti, UP \\ *Corresponding Author
}

Dr Abhishek Kumar Barnwal (MD (Anaesthesiology))

Assistant Professor, Maharishi Vashishtha Autonomous State Medical College, Basti, UP, India

\begin{abstract}
Fractures of neck femur is common fractures in elderly persons. It has always been a challenge for orthopaedic surgeons and it is associated with various medical co-morbidities. Unipolar prosthesis is still extensively used in developing countries in low demanding patients. This study was undertaken to evaluate the functional and radiological outcome of geriatric treated with Austin Moore's prosthesis.

Method: Geriatric patients with femoral neck fractures, managed with hemiarthroplasty using Austin Moore's prosthesis between March 2019 to March 2021 were included in this study. The patients were called up once and were analysed clinically using the Harris hip score. Radiological assessment was done on the Antero-Posterior\& Lateral radiographs of the Hip to look for seating of collar of the prosthesis on the calcar, any degenerative change over the acetabulum, enlargement of the medullary canal, any degenerative change over the acetabulum, subsidence lack of ossification in the fenestration hole of prosthesis \& osteolysis along the stem of prosthesis.

Results: 50 patients fulfilled the inclusion and exclusive criteria and were included in the study, out of which 7 expired and 3 patients didn't turn up for the follow-up. Remaining 40 Patients were included in this study. Mean duration of follow-up in our study was 2yrs. $70 \%$ Showed good condition while $4 \%$ showed poor Harris hip score. Radiologically 24 Patients showed prosthesis collar seating over calcar while 5 patients showed acetabulum changes, 06 had enlarged medullary canal, 05 patients showed osteolysis along the stem of prosthesis and 20 patients showed lack of ossification in the prosthesis fenestration hole. Though the unipolar Austin's Moore's prosthesis faces criticism for causing degenerative arthritis of hip, a year or two year after surgery. Majority of patients showed excellent to good results.

Keywords: Fracture neck of femur, Harris Hip Score, Hemiarthroplasty, Austin Moore's Prosthesis, Degenerative Arthritis, Calcar, Bi-Polar \& THR.
\end{abstract}

\section{Introduction}

Orthopaedics surgeons often encounter elderly patients with fracture neck of femur which is usually associated various medical co-morbidities.
Owing to an increase in the prevalence of osteoporosis in elderly patients, the incidence and the problem following fracture neck femur are on a rise. The incidence of hip fractures differs 
throughout the world. 1.5million of hip fracture occurs worldwide per year. In elderly, hemiarthroplasty is the preferred method of the treatment without prolonged recumbency.

Unipolar prosthesis like, Judet, Thompson and Austin Moore were extensively used in 1950's for the treatment of various hip morbidities \& are still used in developing countries.

\section{Complications of Austin Moore's Prosthesis -}

Following are Complications-

- Persistent pain

- Protrusion-acetabuli due to which many surgeons opt for bipolar or total hipreplacement.

- It is noted that the motion of the head of prosthesis over the weight bearing surface of acetabulum leads to degenerative changes over the hip joint causing secondary osteoarthritis

- Painful hip range of motion.

The factors that are usually considered in choosing the type of prosthesis are

- The general medical condition of the patient,

- Age of the patient,

- The type of fracture,

- Availability of amenities in the health care delivery system,

- Socioeconomic status of the patient.

The study was aimed primarily to evaluate the functional and radiological outcome in old patients of femoral neck fractures managed with Austin Moore's prosthesis.

\section{Material and Methods}

This was retrospective study conducted in the Department of Orthopaedics. Elderly patients (>60yrs) of fracture of neck of femur managed with hemiarthroplasty using Austin Moore's prosthesis \& were operated at our hospital between March 2019 to March 2021. Patients with Poly trauma, presently non ambulatory selected. The data pertaining to patients of fractured neck femur managed with hemiarthroplasty using the Austin Moore's prosthesis was recovered from the medical record room of our hospital. The patients fulfilling the inclusion criteria were called up once after 2 years of surgery. For functional assessment Harris hip scoring system (HHS) was used, and for radiological assessment various parameters like seating of the collar of the prosthesis on the calcar, enlargement of the medullary canal, any degenerative changes over the acetabulum, osteolysis along the stem of prosthesis \& lack of ossification in the fenestration hole of prosthesis. The Harris hip score (HHS) is a clinician-based outcome measurement in cases with hip pathology. It includes pain severity, function which is assessed by daily activities and gait, the absence of deformity (Adduction internal rotational, leg length discrepancy, hip flexion and range of motion).

\section{Radiological Evaluation}

1. Prosthetic implantation

2. The position of stem in varus or valgus.

3. Seating of the prosthesis collar on the calcar.

4. Presence of osteophytes over the acetabulum.

5. Any loosening of the Prosthesis.

6. Enlargement of the Medullary Canal.

7. Prosthesis femoral loosening.

\section{Results}

50 patients fulfilled the inclusion and exclusion criteria were recruited in the study \&of these 7 expired and 3 patients didn't turn up for the follow-up. Remaining 40 Patients were included in this study. The mean follows up of patients $(n=40)$ was 2 years. During radiological assessment seating of the prosthesis. Collar seating over calcar were $60 \%(n=24)$.

\section{Discussion}

In this study, out of 40 patients of fracture neck of femur, the average age was found to be 68.57 in which majority of patients were in the age group between 60-64 years $(n=12)$ followed by $65-67$ $(\mathrm{n}=08)$. There were 20 patients who were more than 70 years of age. 


\section{Radiological Evaluation}

In our study the basis of radiological assessment of patients, we found that majority of patients $60 \%$ has seating of the collar of the prosthesis on the calcar while $10 \%$ patients showed degenerative changes over the acetabulum, 5\% had enlarged medullary canal, $11 \%$ had varus pivoting $8 \%$ hip showed osteolysis along the stem of prosthesis. $64 \%$ of patients i.e.; majority were found to have a good Harris hip score followed by $20 \%$ of patient showed fair and least i.e.; $3 \%$ of patients showed poor Harris hip score.

\section{Conclusion}

In the follow up, most of the patients showed excellent to good results while very few showed poor results. Although most of the patients had difficulty in squatting, which was considered as an essential requirement as per in the scenario. On the basis of our results, we conclude that the use of Austin Moore's prosthesis is a good treatment of choice in old age group with femoral neck fractures.

\section{Hemiarthroplasty using Austin Moore's} prosthesis is a known procedure among Indian Orthopaedics surgeons is because of following reasons -

1) Less time consuming,

2) Less expensive,

3) Easily available,

4) Is performed at a limited resource centre.

\section{Reference}

1. Dhanwal D.K, Siwach r, Dixit V, Mithal A, Jameson K, And Cooper C Arch Osteoporos.

2. Cooper C, Campion G, Melton LJ, $3^{\text {rd }}$ Hip fractures in the elderly: A World-wide Projection.

3. Moore AT, The self locking Metal hip Prosthesis. J.Bone joint Surg Am.

4. Crossman Pt, Khan RJ, Macdowell A, Gradner AC, Reddy NS, Keene GS. A survey of the Treatment of dis-Intracapsular Femoral Neck Fractures in the UK.
5. Victor CR. Unipolar Versus Bipolar Arthroplasty Technique in Orthopaedics September Volume.

6. Kiebzak GM, Beinart GA, Perser K, Et. AL. Under Treatement of osterporosis in men with hip fracture. Arch Intern Med.

7. Calder SJ, Anderson GH, Jagger c, Harper $\mathrm{WM}, \mathrm{Pj}$, Unipolar or Bipolar, prosthesis in intracapsular hip Fractures in octogenary Randomised prospective Study .

8. Vishwanath $\mathrm{C}$ and Mummigatti SB. Comman Study between Austin Moore Prosthesis in Fracture neck of femur.

9. Thompson Fr. Vitallium intramedullary Hip Prosthesis Preliminary Report, NY State j Med.

10. Mulay S, Singh A, Kumar P and Saji M, study of treatment of fracture neck of femur with bipolar/Austin Prosthesis.

11. Krishnan J and Kumarvk. Austin Moore Hemuiarthoplasty visa vis Bipolar arthroplasty in the management of neck of femur fracture.

12. Kalantri a, Barod S, Kothari D, Kothari A, Nagla A, Bhmbani P, Hemiarthroplasty for Intra Capsular Fracture Neck of femur in Elderly Patients.

13. Shah SA, Memon A, Pirwani M. Outcome of femoral neck fracture treated by Austin Moore Hemiarthoplasty in Elderly Patients.

14. Bhat Rs, Mohan Kumar, Cr, HArshraj K, Ramprasad Rai, Jacob IPe, Jabez Gnany and redy VAK, A clinical study on Intracapsular Fracture Neck of femur in elderly treated by Hemiarthroplasty,

15. Agarwal Vk, Singh A, Narula R, Tiwari G, A study of surgical management of fracture neck of femur in elderly with bipolar hemiarthroplasty.

16. Gandhi T, Kosada D, Thakor p, Patel J, Desai $S$ and patwa fracture neck femur treated with Austin Moore prosthesis. 